\title{
Clinical significance of tissue blood flow during esophagectomy by laser Doppler flowmetry
}

Yoshifumi Ikeda, MD

Masanori Niimi, MD, PhD

Shigenao Kan, MD

Tomoo Shatari, MD

Hiroshi Takami, MD

Susumu Kodaira, MD

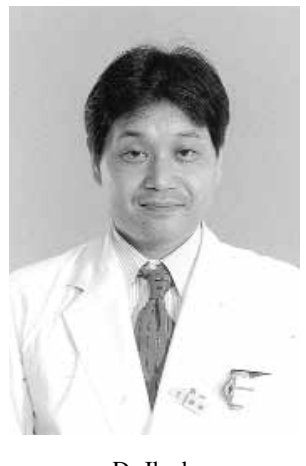

Dr Ikeda
Objectives: We sought to investigate the effect of tissue blood flow on the incidence of anastomotic leakage during esophagectomy.

Methods: Reconstruction was done with a gastric tube, and all cases involved cervical anastomosis. Tissue blood flow of 43 patients was measured with a laser Doppler flowmeter before emplacement and after anastomosis during surgical intervention. The reconstruction route and tissue blood flow before emplacement and that after anastomosis were analyzed as possible factors influencing anastomotic leakage.

Results: Tissue blood flow after anastomosis with leakage was $9.1 \pm 2.0 \mathrm{~mL} / \mathrm{min}$ per $100 \mathrm{~g}$, and that without leakage was $13.7 \pm 2.9 \mathrm{~mL} / \mathrm{min}$ per $100 \mathrm{~g}$. Tissue blood flow with leakage was significantly lower than that without leakage $(P<.01$, unpaired $t$ test). Twenty-one patients had tissue blood flow after anastomosis of greater than $13 \mathrm{~mL} / \mathrm{min}$ per $100 \mathrm{~g}$, and none of them had leakage, whereas 5 patients had blood flow of less than $10 \mathrm{~mL} / \mathrm{min}$ per $100 \mathrm{~g}$, and all 5 had leakage.

Conclusion: Tissue blood flow can be an important and useful indicator of the presence of current anastomotic leakage. Low tissue blood flow after anastomosis may mediate for appropriate surgical or pharmacologic interventions to detect, localize, and counteract leakage.

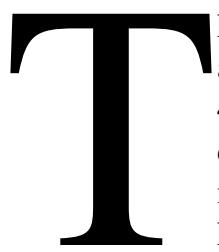

he prognosis of patients with esophageal carcinoma is generally poor, although 5-year survival after surgical intervention has improved to $40 \%$ thanks to multidisciplinary treatment, such as cervicothoracoabdominal lymph node dissection, ${ }^{1}$ radiotherapy, ${ }^{2}$ and chemotherapy ${ }^{3}$ in Japan. The incidence of complications after surgical intervention has decreased because of improved postoperative management and surgical technique. The rate of anastomotic leakage between the cervical esophagus and substitute organ, such as a gastric tube after esophagectomy, has been especially decreased by the development of the circular stapling device. ${ }^{4}$ However, the rate of anastomotic leakage after esophagogastrostomy is reported to be $6 \%$ to $27 \% 5-8$ and it is the highest during general surgery. After gastric mobilization and formation of a gastric tube, in which the left gastroepiploic artery and right and left gastric arteries are usually ligated and divided, the proximal stomach is vascularized by an intramural plexus of vessels and branches from the right gastroepiploic artery. The anastomotic site of the gastric tube is the most distal, relative to its blood supply. ${ }^{9,10}$

Laser Doppler flowmetry has been tested in several experiments and is a valuable tool for determination of vascularization on the basis of tissue blood flow (TBF) in different parts of the gastrointestinal tract. ${ }^{11,12}$ We assessed the relationship between changes in $\mathrm{TBF}$ at the anastomotic site $(\mathrm{TBFa})$ of the gastric tube and 


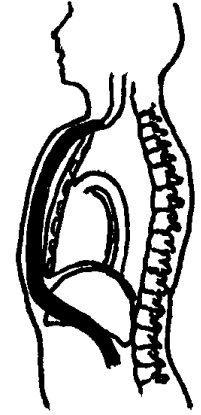

Subcutaneous

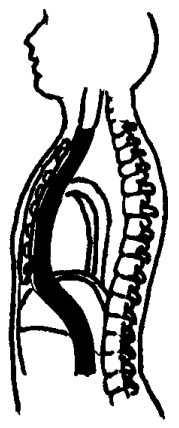

Retrosternal

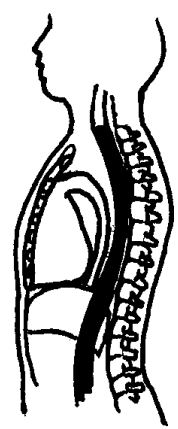

Posterior mediastinal
Figure 1. Reconstruction routes after esophagectomy. Subcutaneous and retrosternal routes are extra-anatomic reconstructions because the gastric tube runs through the subcutaneous tunnel over the sternum and the retrosternal tunnel under the sternum. The posterior mediastinal route is an anatomic reconstruction because a gastric tube is placed in the original position of the esophagus.

the reconstruction route. We also analyzed whether $\mathrm{TBFa}$ levels were associated with anastomotic leakage.

\section{Patients and Methods \\ Patients}

In the 5 years from 1994 to 1998,60 patients with esophageal carcinoma underwent esophagectomy at Teikyo University Hospital. A total of 47,8 , and 5 patients underwent reconstruction with a gastric tube, colon, and jejunum, respectively. Among the gastric tube reconstructions, 4 patients had cervical esophageal carcinoma, and the anastomosis was performed between the pharynx and the gastric tube. Forty-three patients, excluding the 4 patients with cervical esophageal carcinoma, were analyzed in this study. All patients underwent curative esophagectomies, and no patient had clinical evidence of the risk of cardiac function, pulmonary function, or both; operative complications; and preoperative chemotherapy, radiotherapy, or both. The 37 men and 6 women ranged from 39 to 85 years old (mean age, 62 years). On the basis of the clinical stage from the TNM classification of the esophagus ${ }^{13}$ after resection, 5 patients had stage I, 15 had stage IIA, 10 had stage IIB, and 13 had stage III disease.

\section{Esophagectomy}

In all patients a total thoracic esophagectomy and regional lymphadenectomy through a right thoracotomy were performed.

\section{Reconstruction After Esophagectomy}

The gastric tube was constructed by means of ligation of the left gastric artery, part of the right gastric artery, and the left gastroepiploic artery and then fashioned along the greater curvature. Three reconstruction routes (ie, posterior mediastinal, retrosternal, and subcutaneous) can be chosen after esophagectomy (Figure 1). The reconstruction route was selected on the basis of clinical $\mathrm{T}$ and $\mathrm{N}$ factors from the TNM classification of the esophagus ${ }^{13}$ during surgical intervention. Thirteen patients given diagnoses of T3 N1 disease were selected for reconstruction through a subcutaneous

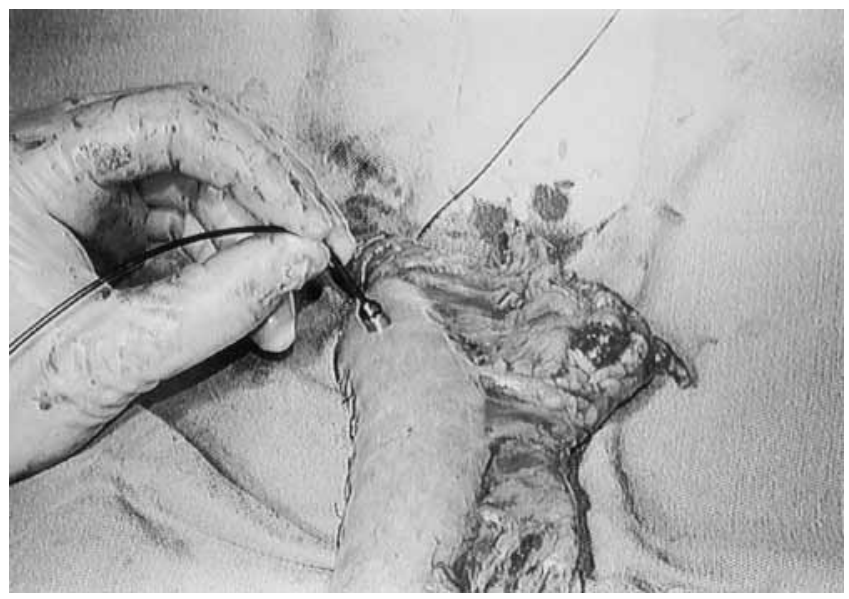

Figure 2. The master probe comes in contact with a gastric tube, and TBF is measured with a laser Doppler flowmeter.

route, 14 with T3 N0 disease through a retrosternal route, and 16 with $\mathrm{T} 1$ or $\mathrm{T} 2$ disease through a posterior mediastinal route. All patients underwent cervical anastomosis in end-to-side fashion with a circular stapling device, such as the EEA (Auto Suture Company Division, United States Surgical Corporation, Norwalk, Conn) or ILS (Johnson-Johnson Medical, Cincinnati, Ohio). Leakage of the anastomosis was defined as a salivary fistula or detected by means of contrast esophagography 7 to 10 days postoperatively.

\section{TBF Analysis}

Blood perfusion of gastric tubes was measured with a helium-neon laser Doppler flowmeter (model ALF21; Advanced Laser Flowmeter Corporation, Tokyo, Japan). The laser light was guided to tissue, and back-scattered light was detected with a master probe (TypeS; Advanced Laser Flowmeter Corporation, Tokyo, Japan; Figure 2). The method relies on the measurement of Doppler frequency shifts in laser light reflected from moving red blood cells, and results are displayed after conversion to units of milliliters per minutes per $100 \mathrm{~g}$ on the basis of the theory proposed by Bonner and colleagues. ${ }^{14}$ Laser Doppler flowmetry at the anastomotic site was measured during the operation. Each measurement was made for 30 seconds, and the procedure was repeated twice. The mean was used as TBF. The first measurements were made after gastric tube construction along the greater curvature. The anastomotic site was defined as $10 \mathrm{~mm}$ from the proposed anastomotic edge. The gastric tube was then brought up to the neck through the subcutaneous, retrosternal, or posterior mediastinal route. The second measurement was made at the neck after cervical anastomosis of the proximal esophagus with the gastric tube.

\section{Statistical Analysis}

Patient groups were compared with the $\chi^{2}$ test, the paired $t$ test, and the unpaired $t$ test with StatView software (SAS Institute Inc, Cary, NC). Values were expressed as means \pm SD.

\section{Results}

Patient Profiles

The rate of anastomotic leakage was 21\% (9/43) in patients with carcinoma in the thoracic esophagus who underwent 
TABLE 1. Patient characteristics divided by presence or absence of leakage

\begin{tabular}{ccccc}
\hline & $\begin{array}{c}\text { Leakage } \\
(\mathbf{n = 9})\end{array}$ & $\begin{array}{c}\text { No leakage } \\
(\mathbf{n = 3 4 )}\end{array}$ & $\begin{array}{c}\text { Total } \\
(\mathbf{n = 4 3 )}\end{array}$ & Significance \\
\hline Sex & & & & \\
Male & $8(22 \%)$ & 29 & 37 & NS \\
Female & $1(17 \%)$ & 5 & 6 & \\
Age (y) & $61.3 \pm 11.3$ & $61.3 \pm 9.9$ & - & NS \\
& $(43-80)^{*}$ & $(39-85)^{*}$ & & \\
pT & & & & \\
T1 & $1(20 \%)$ & 4 & 5 & NS \\
T2 & $2(13 \%)$ & 13 & 15 & \\
T3 & $6(26 \%)$ & 17 & 23 & \\
pN & & & & \\
N0 & $4(20 \%)$ & 16 & 20 & NS \\
N1 & $5(22 \%)$ & 18 & 23 & \\
p Staget & & & & \\
I & $1(20 \%)$ & 4 & 5 & NS \\
IIA & $3(20 \%)$ & 14 & 15 & \\
IIB & $2(20 \%)$ & 8 & 10 & \\
III & $3(23 \%)$ & 8 & 13 & \\
\hline
\end{tabular}

$N S$, Not statistically significant.

*Numbers in parentheses represent ranges.

tAccording to clinical stage on the basis of the TNM classification of the esophagus after resection.

esophageal reconstruction after esophagectomy. We failed to detect a difference between the rate of anastomotic leakage and sex, age, or TNM stage (Table 1).

\section{Patient Characteristics Divided by Reconstruction Route}

The clinical diagnosis of $\mathrm{T}$ and $\mathrm{N}$ factors during surgical intervention did not always agree with the pathologic diagnosis after surgical intervention. Although $\mathrm{T}$ factor was correlated significantly with the reconstruction route, $\mathrm{N}$ factor and TNM stage were not correlated with the reconstruction route (Table 2).

\section{Leakage Versus Reconstruction Route}

Reconstruction through the posterior mediastinal route did not result in anastomotic leakage. The rate of anastomotic leakage was $46 \%(6 / 13)$ in patients undergoing reconstruction through the subcutaneous route and $21 \%$ (3/14) in those undergoing reconstruction through the retrosternal route. The anastomotic leakage correlated significantly with the reconstruction route (Table 3 ).

\section{TBF Measurement}

There were no significant differences in pulse rate, mean arterial pressure, or central venous pressure between the 2 measurement points. The difference of measurements
TABLE 2. Patient characteristics divided by reconstruction route

\begin{tabular}{lcccc}
\hline & $\begin{array}{c}\text { Subcutaneous } \\
(\mathbf{n = 1 3})\end{array}$ & $\begin{array}{c}\text { Retrosternal } \\
(\mathbf{n}=\mathbf{1 4})\end{array}$ & $\begin{array}{c}\text { Posterior } \\
(\mathbf{n}=\mathbf{1 6})\end{array}$ & Significance \\
\hline Sex & & & & \\
Male & 12 & 11 & 14 & NS \\
$\quad$ Female & 1 & 3 & 2 & \\
Age (y) & $60.6 \pm 11.0$ & $58.6 \pm 9.4$ & $64.8 \pm 9.8$ & NS \\
& $(43-80)^{*}$ & $(39-70)^{*}$ & $(51-85)^{*}$ & \\
pT & 1 & 1 & 3 & $P=.014$ \\
T1 & 2 & 3 & 10 & \\
T2 & 10 & 10 & 3 & \\
T3 & & & & \\
pN & 5 & 7 & 8 & NS \\
N0 & 8 & 7 & 8 & \\
N1 & 1 & 1 & 3 & NS \\
p Staget & 4 & 6 & 5 & \\
I & 2 & 3 & 5 & \\
IIA & 6 & 4 & 3 & \\
IIB & & & & \\
III & & & & \\
\hline
\end{tabular}

$N S$, Not statistically significant.

*Numbers in parentheses represent ranges.

tAccording to clinical stage on the basis of the TNM classification of the esophagus after resection.

TABLE 3. Relation between anastomotic leakage and reconstruction route

\begin{tabular}{lcccc}
\hline & \multicolumn{4}{c}{ Route } \\
\cline { 2 - 4 } Leakage & Subcutaneous & Retrosternal & Posterior mediastinal & Total \\
\hline Presence & 6 & 3 & 0 & 9 \\
Absence & 7 & 11 & 16 & 34 \\
Total & 13 & 14 & 16 & 43 \\
\hline
\end{tabular}

$P<.01, \chi^{2}$ test.

repeated twice was $0.27 \pm 0.21 \mathrm{~mL} / \mathrm{min}$ per $100 \mathrm{~g}$, and they varied less than $1.0 \mathrm{~mL} / \mathrm{min}$ per $100 \mathrm{mg}$ in this study.

\section{Changes in TBFa by Reconstruction Route}

TBFa dropped significantly from $14.5 \pm 4.3$ to $11.8 \pm 3.1$ $\mathrm{mL} / \mathrm{min}$ per $100 \mathrm{~g}(P<.05$, paired $t$ test $)$ in reconstruction through the subcutaneous route and from $14.7 \pm 4.4$ to 12.2 $\pm 3.3 \mathrm{~mL} / \mathrm{min}$ per $100 \mathrm{~g}(P<.05$, paired $t$ test $)$ in reconstruction through the retrosternal route. In reconstruction through the posterior mediastinal route, TBFa dropped from $14.5 \pm 2.6$ to $13.9 \pm 2.4 \mathrm{~mL} / \mathrm{min}$ per $100 \mathrm{~g}$. However, we failed to detect a significant difference $(P=.35$, paired $t$ test). TBFa after anastomosis by means of reconstruction through the posterior mediastinal route $(13.9 \pm 2.4 \mathrm{~mL} / \mathrm{min}$ per $100 \mathrm{~g}$ ) was significantly higher than in reconstruction 


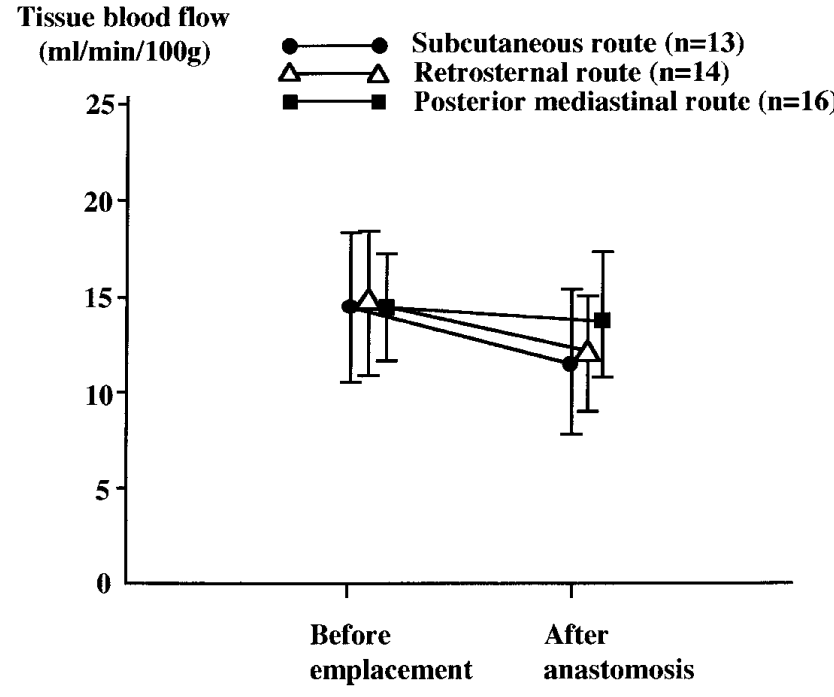

Figure 3. Changes of TBFa before emplacement and after anastomosis through each route. TBFa after anastomosis has significantly dropped with the reconstruction through the subcutaneous and retrosternal routes $(P<.05$, paired $t$ test). TBFa after anastomosis reconstruction through the subcutaneous routes was significantly lower than that through the posterior mediastinal route $(P<.05$, unpaired $t$ test $)$.

TABLE 4. Relation between TBFa with and without leakage

\begin{tabular}{lccc}
\hline & Leakage & No leakage & $\boldsymbol{P}$ value \\
\hline TBFa before emplacement & $11.2 \pm 2.4$ & $15.4 \pm 3.5$ & $.0016^{*}$ \\
$\quad$ Subcutaneous route & $11.4 \pm 1.5$ & $17.1 \pm 4.1$ & $.0091^{*}$ \\
Retrosternal route & $10.8 \pm 4.2$ & $15.8 \pm 4.0$ & $.0813 \dagger$ \\
$\quad$ Posterior mediastinal route & - & $14.5 \pm 2.6$ & - \\
TBFa after anastomosis & $9.1 \pm 2.0$ & $13.7 \pm 2.9$ & $.0001^{*}$ \\
\hline
\end{tabular}

*Student $t$ test.

tWelch $t$ test.

through the subcutaneous route $(11.8 \pm 3.1 \mathrm{~mL} / \mathrm{min}$ per 100 $\mathrm{g} ; P<.05$, unpaired $t$ test; Figure 3).

\section{TBFa Before Emplacement}

In reconstruction through the subcutaneous route, $\mathrm{TBFa}$ before emplacement with anastomotic leakage was $11.4 \pm$ $1.5 \mathrm{~mL} / \mathrm{min}$ per $100 \mathrm{~g}$, and that without anastomotic leakage was $17.1 \pm 4.1 \mathrm{~mL} / \mathrm{min}$ per $100 \mathrm{~g}$. TBFa before emplacement with anastomotic leakage was significantly lower than that without anastomotic leakage $(P<.01$, unpaired $t$ test). In reconstruction through the retrosternal route, $\mathrm{TBFa}$ before emplacement with anastomotic leakage was $10.8 \pm$ $4.2 \mathrm{~mL} / \mathrm{min}$ per $100 \mathrm{~g}$, and that without anastomotic leakage was $15.8 \pm 4.0 \mathrm{~mL} / \mathrm{min}$ per $100 \mathrm{~g}$. TBFa before emplacement with anastomotic leakage was lower than that without anastomotic leakage (Table 4).

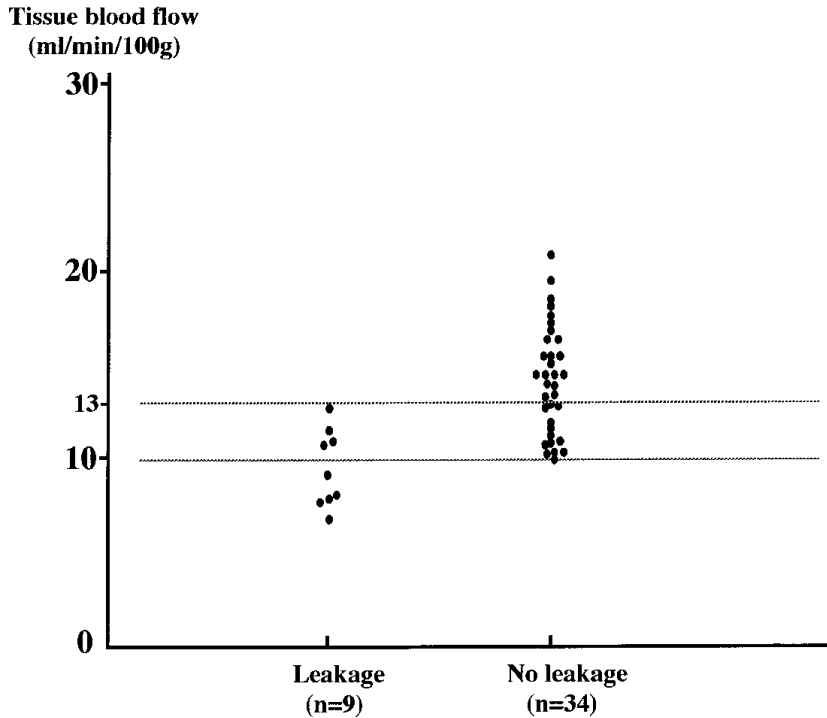

Figure 4. TBFa after anastomosis in patients with and without anastomotic leakage. Twenty-one patients had TBFa after anastomosis of greater than $13 \mathrm{~mL} / \mathrm{min}$ per $100 \mathrm{~g}$, and none of them had leakage, whereas 5 patients had TBFa of less than $10 \mathrm{~mL} / \mathrm{min}$ per $100 \mathrm{~g}$, and all 5 had leakage.

\section{TBFa After Anastomosis}

TBFa after anastomosis with anastomotic leakage was $9.1 \pm$ $2.0 \mathrm{~mL} / \mathrm{min}$ per $100 \mathrm{~g}$, and that without anastomotic leakage was $13.7 \pm 2.9 \mathrm{~mL} / \mathrm{min}$ per $100 \mathrm{~g}$. TBFa after anastomosis with anastomotic leakage was significantly lower than that without anastomotic leakage $(P<.01$, unpaired $t$ test; Table 4). Twenty-one patients had TBFa after anastomosis of greater than $13 \mathrm{~mL} / \mathrm{min}$ per $100 \mathrm{~g}$, and none of them had leakage, whereas 5 patients had less than 10 $\mathrm{mL} / \mathrm{min}$ per $100 \mathrm{~g}$, and all 5 had leakage (Figure 4).

\section{Discussion}

In our study the rate of anastomotic leakage was $21 \%$, which is high among previous reports, because there were a number of cases reconstructed through the subcutaneous route, and all cases involved cervical anastomosis. The leakage rate in reconstruction through the retrosternal and posterior mediastinal routes in our patients was $10 \%$, and all posterior mediastinal reconstructions were successful (Table 3). Although the posterior mediastinal route has an advantage in anastomotic leakage, secondary dysphasia caused by intrathoracic locoregional tumor recurrence developed because the gastric tube runs along the original esophagus. ${ }^{15,16}$ In contrast to anatomic reconstruction with the posterior mediastinal route, extra-anatomic reconstruction through a subcutaneous or retrosternal route avoids malignant dysphasia because the gastric tube runs away from the recurrent site. In advanced carcinoma in the upper- 
third thoracic esophagus or with lymph node metastasis in the upper mediastinum, we selected the subcutaneous route.

However, the clinical diagnosis of $\mathrm{T}$ and $\mathrm{N}$ factors during surgical intervention did not always agree with the pathologic diagnosis after surgical intervention. Although pathologic T3 cases abounded for extra-anatomic routes, pathologic $\mathrm{N}$ factor was not correlated with the reconstruction route (Table 2 ). The degree of invasiveness into the surrounding tissue may increase the operative complications and influence the incidence of leakage. There was not statistical power to exclude a difference.

Measurement of TBF with laser Doppler flowmetry is simple and noninvasive. When the master probe is used, movement artifacts are few, and pressure between the surface and the probe is constant. In our study the operative judgment of perfusion of the gastric tube made by the same surgeon showed good correlation with laser Doppler flowmetry. When the same site is examined several times, changes in recorded values are dependent on the stability of the apparatus and biologic variations within the subject. The reliability of the double measurements of TBF varied less than $1.0 \mathrm{~mL} / \mathrm{min}$ per $100 \mathrm{mg}$ in this study. TBF measurements were influenced by pulse rate, mean arterial pressure, and automatic nervous system stimulation. It is important to obtain measurements in a stabilized condition. The time of this procedure is less than 15 minutes, and the cost of this technique is cheap because the master probe is usable. Other methods of estimating the vascularization, such as ultrasound Doppler system, tissue oxygen tension measurements, venous outflow recordings, and fluorescein flowmetry, have been reported to correlate well with measurements of TBF. ${ }^{12,17-19}$ Conflicting evidence suggests that blood flow at depths between 1 and $6 \mathrm{~mm}$ is measured with a laser in laser Doppler flowmetry, ${ }^{20}$ and it is not known whether mucosa side blood flow is detected by measurement from the serosal side of the stomach. There is autoregulation of mucosa perfusion at high gastric flow rates, but at lower flow rates, mucosa perfusion enjoys a linear relationship with total arterial flow. ${ }^{21,22}$ Then the reduction in arterial flow in a gastric tube makes the gastric mucosa lose its autoregulatory ability, and serosal and mucosa perfusion would be related to each other. ${ }^{22}$ We also demonstrated the correlation between mucosa and serosal perfusion after mobilization of the gastric tube. ${ }^{23}$ In measurement of blood perfusion, a relative perfusion value expressed as the percentage of the basis of the gastric tube was usually chosen. However, TBF of the gastric tube was decreased because of tension and an angle to the stomach muscle when it was brought up to the neck, and TBF on the basis of the gastric tube for relative blood flow is changed. Therefore, comparing a value after anastomosis with the value before emplacement is difficult. Because of the above reasons, absolute serosal perfusion values were simply analyzed for measurement of TBF of the gastric tube. Although the preparation of the gastric tube was performed with the same procedure, $\mathrm{TBFa}$ before emplacement was scattered because the blood flow of the right gastroepiploic artery was individually different.

We clearly demonstrated 2 clinically important observations. First, TBFa significantly decreased when the gastric tube ran through extra-anatomic reconstruction, such as the subcutaneous or retrosternal route (Figure 3). Second, low TBFa after anastomosis was associated with a high leak rate, and all patients with TBFa after anastomosis of less than 10 $\mathrm{mL} / \mathrm{min}$ per $100 \mathrm{~g}$ had anastomotic leakage (Figure 4).

When TBFa after anastomosis is low, we recommend investigating for a possible anastomotic leakage and considering the necessity of additional surgical treatment, pharmacologic treatment, or both.

TBFa after anastomosis should be maintained at greater than $10 \mathrm{~mL} / \mathrm{min}$ per $100 \mathrm{~g}$ because all patients with values of less than this limit had anastomotic leakage. Therefore, when TBFa after anastomosis is lower than $10 \mathrm{~mL} / \mathrm{min}$ per $100 \mathrm{~g}$, surgical maneuvers, pharmacologic maneuvers, or both should be applied to increase TBFa. Surgically, the condition of a gastric tube in the reconstructed tunnel can be inspected for possible obstruction. Pharmacologically, alprostadil (prostaglandin $\mathrm{E}_{1}$ ), dopamine, or both, may improve blood flow in the gastric tube. ${ }^{23,24}$ In the past 2 years, we had 2 patients in whom TBFa after anastomosis was quite a bit lower than $10 \mathrm{~mL} / \mathrm{min}$ per $100 \mathrm{~g}$. These patients were given alprostadil intravenously at a rate of 0.02 $\mathrm{mL} \cdot \mathrm{kg}^{-1} \cdot \mathrm{min}^{-1}$. TBFa after anastomosis improved from 7.3 and 7.9 to 11.2 and $12.0 \mathrm{~mL} / \mathrm{min}$ per $100 \mathrm{~g}$, respectively. Alprostadil was infused continuously until postoperative day 2 . The patients recovered without any complications, including anastomotic leakage. When TBFa after anastomosis is still less than $10 \mathrm{~mL} / \mathrm{min}$ per $100 \mathrm{~g}$ after additional surgical maneuvers, pharmacologic maneuvers, or both, we must be careful to ensure complete drainage when preparing for anastomotic leakage.

We conclude that TBF in the gastric tube can be safely and reliably measured at the time of esophagectomy and that very low flow levels may be an important indicator of potential leakage. Larger studies are required to investigate the ability to modulate these blood flow levels with alterations of surgical technique and postoperative medical management.

\section{References}

1. Matsubara T, Ueda M, Nagao N, Takahashi T, Nakajima T, Nishi M. Cervicothoracic approach for total mesoesophageal dissection in cancer of the thoracic esophagus. J Am Coll Surg. 1998;187:238-45.

2. Tsunemoto H, Ishikawa T, Morita S, Kitagawa T, Tsujii H. Indications of particle radiation therapy in the treatment of carcinoma of the esophagus. Int J Radiat Oncol Biol Phys. 1992;22:321-4.

3. Ando N, Iizuka T, Kakegawa T, Isono K, Watanabe H, Ide H, et al. A randomized trial of surgery with and without chemotherapy for localized squamous carcinoma of the thoracic esophagus: the Japan 
Clinical Oncology Group Study. J Thorac Cardiovasc Surg. 1997; 114:205-9.

4. Sugimachi K, Ohno S, Maekawa S, Mori M, Kuwano H, Ueo H. Safety of EEA staplers for anastomosis between upper esophagus and the gastric tube. J Surg Oncol. 1990;43:40-4.

5. Launois B, Paul JL, Lygidakis NJ, Malledant Y, Grossetti D, Delarue D. Results of the surgical treatment of carcinoma of the esophagus. Surg Gynecol Obstet. 1983;156:753-60.

6. Lee Y, Fujita H, Yamana H, Kakegawa T. Factors affecting leakage following esophageal anastomosis. Surg Today. 1994;24:24-9.

7. Patil PK, Patel SG, Mistry RC, Deshpande RK, Desai PB. Cancer of the esophagus: esophagogastric anastomotic leak-a retrospective study of predisposing factors. J Surg Oncol. 1992;49:163-7.

8. Anikin VA, McManus KG, Graham AN, McGuigan JA. Total thoracic esophagectomy for esophageal cancer. J Am Coll Surg. 1997;185:525-9.

9. Pierie JP, De Graaf PW, Poen H, Van der Tweel I, Obertop H. Impaired healing of cervical oesophagogastrostomies can be predicted by estimation of gastric serosal blood perfusion by laser Doppler flowmetry. Eur J Surg. 1994;160:599-603.

10. Korenaga D, Toh Y, Maekawa S, Ikeda T, Sugimachi K. Intra-operative measurement of the tissue blood flow for evaluating blood supply to the gastric tube for esophageal reconstruction. Hepatogastroenterology. 1998:45:2179-80.

11. Sugimachi K, Yaita A, Ueo H, Natsuda Y, Inokuchi K. A safer and more reliable operative technique for esophageal reconstruction using a gastric tube. Am J Surg. 1980;140:471-4.

12. Imamura M, Ohishi K, Tobe T. Retrosternal esophagogastrostomy with the EEA stapler. Surg Gynecol Obstet. 1987;164:368-71.

13. Hermanek P, Sobin LH, International Union Against Cancer (UICC). TNM classification of malignant tumors. 4th ed. 2nd revision. Berlin: Springer; 1992.

14. Bonner RF, Clem TR, Bown PD. Laser-Doppler continuous real-time monitor of pulsatile and mean blood flow in tissue microcirculation.
In: Chen SH, Chu B, Nossal R, editors. Scattering techniques applied to supramolecular and nonequilibrium systems. New York: Plenum; 1981. p. 685-701.

15. van Lanscot JJB, Hop WCJ, Voormolen MHJ, van Deelen RAJ, Blomjous JGAM, Tilanus HW. Quality of palliation and possible benefit of extra-anatomic reconstruction in recurrent dysphagia after resection of carcinoma of the esophagus. J Am Coll Surg. 1994;179:705-13.

16. van Lanscot JJB, van Blankenstein M, Oeis HY, Tilanus HW. Randomized comparison of prevertebral and retrosternal gastric tube reconstruction after resection of oesophageal carcinoma. Br J Surg. 1999;86:102-8.

17. Ahn $\mathrm{H}$, Ivarsson LE, Johansson $\mathrm{K}$, Lindhagen $\mathrm{J}$, Lundgren $\mathrm{O}$. Assessment of gastric blood flow with laser Doppler flowmetry. Scand J Gastroenterol. 1988;23:1203-10.

18. Pierie JP, de Graaf PW, Poen H, van der Tweel I, Obertop H. Incidence and management of benign anastomotic stricture after cervical oesophagogastrostomy. Br J Surg. 1993;80:471-4.

19. Pierie JP, de Graaf PW, Poen H, Van der Tweel I, Obertop H. Impaired healing of cervical oesophagogastrostomies can be predicted by estimation of gastric serosal blood perfusion by laser Doppler flowmetry. Eur J Surg. 1994;160:599-603.

20. Wardell K, Jakobsson A, Nilsson GE. Laser Doppler perfusion imaging by dynamic light scattering. IEEE Trans Biomed Eng. 1993;40:309-13.

21. Kiel JW, Riedel GL, Shepherd AP. Autoregulation of canine gastric mucosa blood flow. Gastroenterology. 1987;93:12-20.

22. Boyle NH, Pearce A, Hunter D, Owen WJ, Mason RC. Scanning laser Doppler flowmetry and intraluminal recirculating gas tonometry in the assessment of gastric and jejunal perfusion during oesophageal resection. Br J Surg. 1998;85:1407-11.

23. Hanashi T. An experimental study on circulation in stomach roll by Laser-Doppler flowmetry. Teikyo Med J. 1997;20:135-47.

24. Duda G, Huesken JE, Harmon JW. Effects of prostaglandins on esophageal blood flow. J Surg Res. 1998;44:371-81.

\section{Timely}

The Journal of Thoracic and Cardiovascular Surgery delivers the information you need now. Articles usually appear within four months of acceptance. 